\title{
Cardiovascular System Findings Completion Status
}

National Cancer Institute

\section{Source}

National Cancer Institute. Cardiovascular System Findings Completion Status. NCI

Thesaurus. Code C124006.

A term used to describe the state or condition of the completeness of the cardiovascular system findings data. 